\title{
Development of a multiplex methylation-specific PCR as candidate triage test for women with an HPV-positive cervical scrape
}

Suzanne Snellenberg, Lise MA De Strooper, Albertus T Hesselink, Chris JLM Meijer, Peter JF Snijders, Daniëlle AM Heideman and Renske DM Steenbergen*

\begin{abstract}
Background: Quantitative methylation-specific PCR (qMSP) analysis for determining the methylation status of (candidate) tumor suppressor genes has potential as objective and valuable test to triage high-risk human papillomavirus (hrHPV) positive women in cervical screening. Particularly combined methylation analysis of a panel of genes shows most promising clinical performance, with sensitivity levels that equal or exceed that of cytology. However, the wide application of such methylation marker panels is hampered by the lack of effective multiplex assays allowing simultaneous methylation detection of various targets in a single reaction. Here, we designed and analyzed a multiplex qMSP assay for three genes whose methylation was previously found to be informative for cervical (pre)cancer (i.e. CADM1, MAL and hsa-miR-124-2) as well as a reference gene $\beta$-actin. Based on our experience, we discuss the optimization of the parameters that provide a practical approach towards multiplex qMSP design.
\end{abstract}

Methods: Primers and PCR reagents were optimized for multiplex qMSP purposes and the resulting assay was analytically validated on serial dilutions of methylated DNA in unmethylated DNA, and compared with singleplex counterparts on hrHPV-positive cervical scrapings.

Results: Upon optimization, including primer redesign and primer limiting assays, the multiplex qMSP showed the same analytical performance as the singleplex qMSPs. A strong correlation between the obtained normalized ratios of the singleplex and multiplex qMSPs on cervical scrapes was found for all three markers: CADM1 $\left(R^{2}=0.985\right)$, MAL $\left(R^{2}=0.986\right)$ and hsa-miR-124-2 $\left(R^{2}=0.944\right)$.

Conclusion: Multiplex qMSP offers a promising approach for high-throughput diagnostic analysis of the methylation status of multiple genes, which after proper design and validation can be equally specific, sensitive and reproducible as its singleplex versions.

Keywords: Cervical cancer, HPV testing, DNA methylation, Promoter, CADM1, MAL, hsa-miR-124-2, Multiplex qMSP, Primer/probe design, 7500Fast ABI system

\section{Background}

Persistent infection with high-risk human papillomavirus (hrHPV) types is causally involved in the development of both squamous cell carcinoma (SCC) and adenocarcinoma (AdCA) of the cervix $[1,2]$. Testing for hrHPV in cervical screening programs results in earlier detection of clinically relevant cervical lesions (high grade cervical

\footnotetext{
* Correspondence: r.steenbergen@vumc.nl

Department of Pathology, VU University Medical Center, Amsterdam, The Netherlands
}

intraepithelial neoplasia or cancer (CIN2+) than cytology $[3,4]$. This provides a higher reassurance of low cervical cancer risk in test negative women $[4,5]$. However, only a fraction of hrHPV positive women will have or develop CIN2+, arguing for the use of additive disease markers to distinguish the subgroup of women having a high likelihood of high-grade disease in need of further gynecologic examination.

Epigenetic silencing of tumor suppressor genes by DNA methylation in cervical (pre)cancers has been 
shown to provide disease biomarkers with great potential applicable to both clinician-collected cervical scrape samples and self-collected cervico-vaginal specimens [6-9]. Methylation of CpG islands within promoter regions of genes and microRNAs such as CADM1, MAL, and hsa-miR-124-2, reflects mechanistically relevant events for cervical carcinogenesis $[8,10,11]$. Until now, DNA methylation of many genes has been analyzed, often by quantitative methylation-specific PCR (qMSP), on tissue and/or cervical scrape samples (reviewed by Wentzensen et al. [12]). Recent studies indicate that most optimal sensitivity rates for $\mathrm{CIN} 2+$ can only be obtained by testing for a combination of methylation markers [13-16]. However, determining the methylation status of multiple methylation markers separately is time consuming and relatively large amounts of sample material are needed. Multiplexing allows for more methylation targets to be analyzed using a single aliquot of sample material with potential for reducing target-to-target differences and monitoring sample adequacy for PCR purpose by an internal reference gene, thereby saving material, time and costs and improving quality control.

Here, we describe the consecutive experimental steps to set up a multiplex qMSP for CADM1, MAL and hsamiR-124- 2 and the reference gene $\beta$-actin (ACTB) with equal analytical performance as the individual singleplex qMSP assays. Following analytical validation, a proof of concept analysis was performed on cervical scrapings. The findings provide a practical guide for qMSP design and demonstrate that multiplex qMSP can be used for high-throughput diagnostic analysis, without the risk of a decrease in assay performance.

\section{Methods \\ Cell cultures}

Primary human foreskin keratinocytes (EKs) and the cervical cancer cell line SiHa were cultured as described previously [17].

\section{Cervical scrapings}

Cervical scrapings were obtained from the populationbased cervical screening trial POBASCAM, registered as ISRCTN20781131 [18]. We randomly selected 33 cervical scrapings of GP5+/6+-PCR hrHPV-positive women with normal cytology without evidence of $\mathrm{CIN} 2+$ up to the next screening round after 5 years (i.e., two had histologically CIN1, 31 had histologically no CIN) and 12 scrapings classified as mild dyskaryosis or worse of hrHPV-positive women with CIN3 $(\mathrm{n}=11)$ or SCC $(\mathrm{n}=1)$ diagnosed within 18 months of follow-up. This study followed the ethical guidelines of the Institutional Review Board of the $\mathrm{VU}$ University Medical Center.

\section{DNA extraction, HPV typing and bisulfite modification}

DNA was isolated from cervical scrapes using NucleoSpin 96 Tissue kit (Macherey-Nagel) and a Microlab Star robotic system (Hamilton) according to manufacturers' instructions. Genomic DNA from cell cultures was isolated with UltraPure ${ }^{\mathrm{TM}}$ Phenol:Chloroform:Isoamyl Alcohol (Invitrogen Life Science Ltd, Carlsbad, CA USA). HPV detection and genotyping was performed using the general primer GP5+/6+-PCR enzyme immunoassay, followed by reverse line blot analysis [19]. Furthermore, genomic DNA from tissue specimens and cell lines $(0.5$ to $2 \mu \mathrm{g})$ were subjected to bisulfite treatment with the EZ DNA Methylation Kit ${ }^{\mathrm{TM}}$ (Zymo Research, Orange, CA, USA). Standard curves were generated by spiking methylated DNA from the SiHa cell line in unmethylated DNA from EKs in order to obtain a serial dilution of $50 \mathrm{ng}$ to $0.25 \mathrm{ng}$ methylated DNA in a total of $50 \mathrm{ng}$ of DNA.

\section{Quantitative MSP (qMSP) analysis}

For the amplification reaction $2.5 \mu \mathrm{l}$ bisulfite treated DNA (50 ng) was added to $10 \mu \mathrm{l}$ amplification mix containing 1x Quantitect Probe mix (Qiagen, Leusden, The Netherlands), various primer concentrations (50 - 400 $\mathrm{nM}$ ) and $200 \mathrm{nM}$ of the hydrolysis probe. Sequences of primers and hydrolysis probes are available on request. Amplification and real-time measurement was performed in the 7500Fast ABI system (Applied Biosystems, Foster City, CA, USA), using the following conditions; $15 \mathrm{~min}$ at $95^{\circ} \mathrm{C}$ followed by 40 cycles of $15 \mathrm{~s}$ at $95^{\circ} \mathrm{C}$ and $1 \mathrm{~min}$ at $60^{\circ} \mathrm{C}$.

\section{Multiplex qMSP analysis}

Multiplex qMSP analysis was mainly done using QuantiTect Muliplex mix (Qiagen), unless specified otherwise. The other master mixes tested were EpiTect MethyLight mix (Qiagen), iQ Multiplex Powermix (Bio-Rad, Veenendaal, The Netherlands) or Genotyping Master Mix (Applied Biosystems). For the amplification reaction, $2.5 \mu \mathrm{l}$ bisulfite treated DNA (50 ng) was added to $10 \mu \mathrm{l}$ amplification mix containing 1x Multiplex mix, $400 \mathrm{nM}$ of MAL and hsa-miR-124-2 primer, $200 \mathrm{nM}$ of ACTB and CADM1 primer, and $200 \mathrm{nM}$ hydrolysis probe of each target with the following conditions; 10 or $15 \mathrm{~min}$ at $95^{\circ} \mathrm{C}$ followed by 40 cycles of $15 \mathrm{~s}$ or $60 \mathrm{~s}$ at $94^{\circ} \mathrm{C}$ or $95^{\circ} \mathrm{C}$ and $60 \mathrm{~s}$ or $90 \mathrm{~s}$ at $60^{\circ} \mathrm{C}$, depending on the buffer system used.

\section{Data analysis}

Methylation values were normalized to the reference gene ACTB using the comparative $\mathrm{Cq}$ method $\left(2^{-\Delta \mathrm{CQ}}\right)$ [20]. The amplification efficiencies were calculated by $\mathrm{E}=\left(10^{(-1 / \text { Slope })}-1\right) \times 100 \%$ for all serial dilutions [21]. Correlations $\left(R^{2}\right)$ of the serial dilutions and normalized 
ratios between the multiplex and singleplex qMSP of cervical scrapings were determined using Microsoft $^{\circledR}$ Office Excel 2003 (SP3).

\section{Results}

\section{Parameters important for multiplex qMSP design}

The various parameters important for multiplex qMSP development, as summarized in Figure 1, are described in the following section.

First, multiplex qMSP development requires the selection of dyes that give a good spectral separation to avoid overlap of the signals of different targets. The ABI7500Fast Real-Time PCR System, used in this study, has five different channels. One channel is used by ROX (emission maximum at $602 \mathrm{~nm}$ ), a dye present in the master mix to correct for pipetting errors (passive reference), leaving four channels to be used for target detection. In this study, FAM $(520 \mathrm{~nm})$, JOE $(548 \mathrm{~nm})$, Dragon Fly
Orange (DFO; $576 \mathrm{~nm})$ and CY5 $(650 \mathrm{~nm})$ were used. It should be taken into account that the fluorescence intensities $(\Delta \mathrm{Rn})$ differ between these four dyes, which can affect the Quantification Cycle $(\mathrm{Cq})$ values.

The second step involves the selection of primer pairs for all targets that display nearly identical annealing temperatures in order to ensure similar amplification efficiencies. Singleplex qMSPs for CADM1, MAL and hsa-miR-124-2 have been described previously [9,11], though primers differed in their annealing temperatures as determined using Primer Express version 3.0 (Applied Biosystems). Whereas the annealing temperatures of the hsa-miR-124-2 primers and primers of ACTB were comparable $\left(58.2-59.9^{\circ} \mathrm{C}\right)$, the CADM1 and MAL primers had lower annealing temperatures $\left(54-57^{\circ} \mathrm{C}\right)$. When testing these primer pairs in a multiplex qMSP at an annealing temperature of $60^{\circ} \mathrm{C}$, no linear amplification curves were seen for CADM1 and MAL (Figure 2A, B).

Primers:

Step 1. Primer and probe design

- Include as many $\mathrm{CpG}$ sites as possible (at least two), preferably at the

3'-end

- GC content: $30-80 \%$

- Length 9-40 bases

- $<2{ }^{\circ} \mathrm{C}$ difference in $\mathrm{Tm}$ between all primers

- Amplicon length: $<150 \mathrm{bp}$

Probes:

- Select fluorescent label with corresponding BHQ for the different targets

- Tm $10{ }^{\circ} \mathrm{C}$ higher than primer $\mathrm{Tm}$

- Number C's > G's

- No G at 5 'end

- Determine stabilities of hairpins, self- and cross-dimers between all primers and probes to ensure minimal intramolecular interactions

- MethBLAST search to ensure target specificity

\begin{tabular}{|c|}
\hline $\begin{array}{l}\quad \text { Step 2. Singleplex qMSP } \\
\text { - Amplify all loci individually using same conditions } \\
\text { - Run dilutions series of methylated DNA in unmethylated DNA } \\
\text { Criteria: } \\
\text { - } \mathrm{R}^{2}<0.98 \\
\text { - Slope: between }-3.1 \text { and }-3.9 \\
\text { - PCR efficiency: } 80-110 \% \\
\text { - Perform primer-limiting-assay: } 0.05-0.4 \mu \mathrm{M}\end{array}$ \\
\hline $\begin{array}{l}\quad \text { Step 3. Validation Multiplex qMSP } \\
\left.\text { - Run dilutions series of methylated DNA in unmethylated DNA (and } \mathrm{H}_{2} \mathrm{O}\right) \\
\text { Criteria } \\
\text { - } \mathrm{R}^{2}<0.98 \\
\text { - Slope: between }-3.1 \text { and }-3.9 \\
\text { - PCR efficiency: } 80-110 \%\end{array}$ \\
\hline
\end{tabular}

Figure 1 Practical approach to multiplex qMSP development. Partially adapted from Henegariu [22]. 

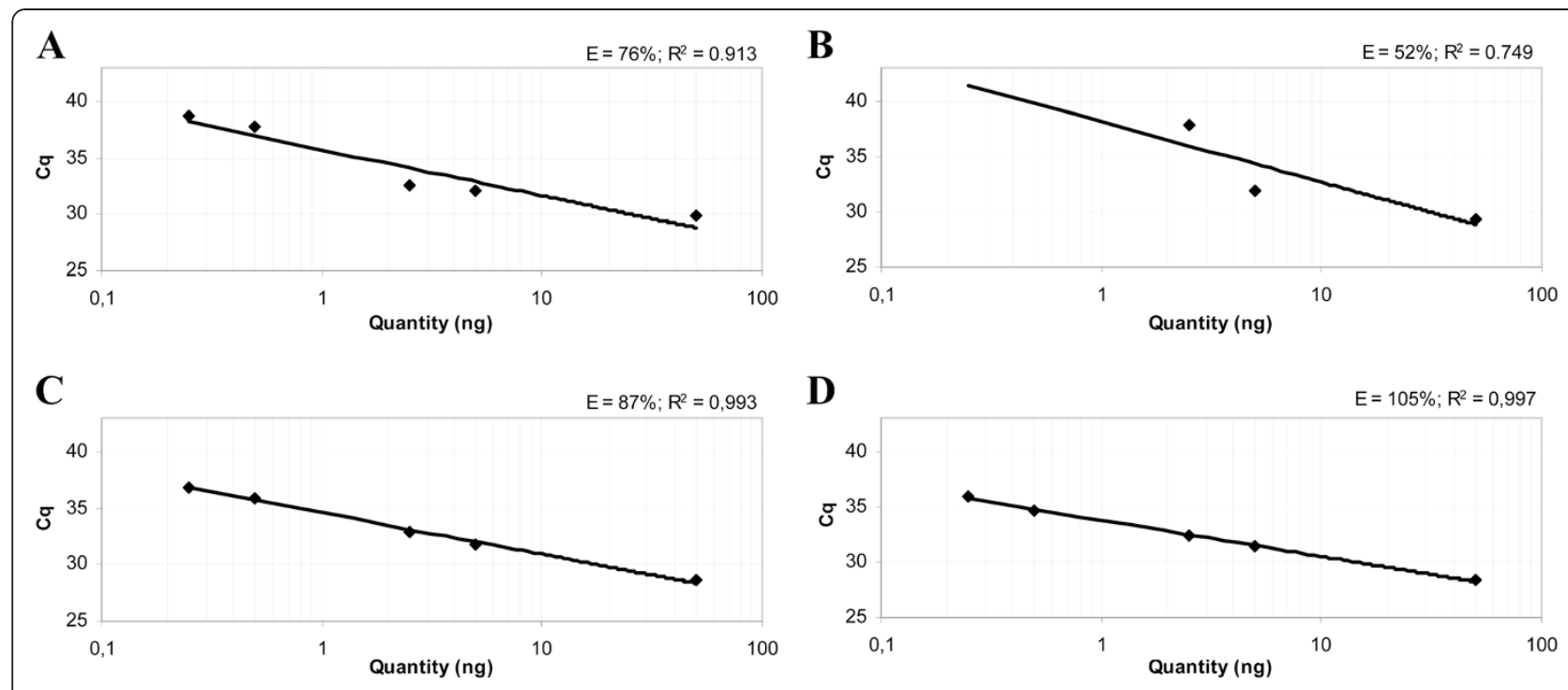

Figure 2 Standard curves of CADM1 and MAL in a multiplex qMSP with ACTB ${ }^{*}$ tested on a serial dilution series of methylation positive SiHa DNA in methylation negative DNA of primary keratinocytes. Standard curve of CADM1 (A) and MAL (B) with the previously described primers ${ }^{9}$. CADM1 (C) and MAL (D) primers with nearly identical annealing temperatures as ACTB primers. For the dilution series the PCR efficiencies were calculated by $E=\left(10^{\left(-1 / \text { llope }_{-}\right.}-1\right) \times 100 \%$. The $\mathrm{qPCR}$ efficiencies increased from $76 \%$ to $87 \%$ for CADM1 and $52 \%$ to $105 \%$ for MAL.) Multiplex GMSP was performed with an ACTB primer concentration of $200 \mathrm{nM}$.

Therefore, CADM1 and MAL primers were redesigned to obtain primers with annealing temperatures comparable to that of ACTB and hsa-miR-124-2. For primer (re)design the following parameters were taken into account: 1 ) inclusion of as many CpG sites as possible (at least two), preferably at the 3'-end [23]; 2) maximum amplicon length of $150 \mathrm{bp}$, based on the fact that DNA is strongly degraded upon bisulfite conversion; 3) minimization of formation of intramolecular interactions within the primer (hairpins), dimerization with itself (self-dimers) or with primers for the other targets (cross-dimers) and 4) a methBLAST search at http://medgen.ugent.be/methBLAST/ to ensure target specificity of primers.

Following primer redesign, the PCR efficiencies increased from $75 \%$ to $95 \%$ and $52 \%$ to $105 \%$ for CADM1 and MAL, respectively, in the multiplex qMSP (Figure 2C, D).

Next a primer limiting assay was performed to determine at which primer concentration an early plateau phase is reached, resulting in a lower $\Delta \mathrm{Rn}$, with an unchanged Cq. This optimization is required because amplification of most abundant targets may result in depletion of the dNTPs present in the reaction mixture, thereby hampering amplification of other targets (Figure 3A). To determine the lowest primer concentration that does not affect the Cq value for all four targets, singleplex qMSP was performed with different primer concentrations, ranging from $400 \mathrm{nM}$ to $50 \mathrm{nM}$. For ACTB the same Cq was obtained at primer concentrations of 400,300 and $200 \mathrm{nM}$, with a lower $\Delta \mathrm{Rn}$ observed at 300 and $200 \mathrm{nM}$ (Figure 3B). The Cq increased at a primer concentration of $100 \mathrm{nM}$. Hence, $200 \mathrm{nM}$ was selected as the minimum concentration for amplifying ACTB in a multiplex reaction. When an ACTB-MAL multiplex qMSP was performed with an ACTB-primer concentration of $200 \mathrm{nM}$, MAL is efficiently amplified (Figure 3C). For CADM1, MAL and hsa-miR-124-2 the minimum primer concentrations were $200 \mathrm{nM}, 400 \mathrm{nM}$ and $400 \mathrm{nM}$ (Figure 3D-F), respectively.

To optimize the multiplex qMSP analysis, various commercially available TaqMan buffer systems were compared. For this purpose, the EpiTect MethyLight Mix (Qiagen), the iQ Multiplex Powermix (Bio-Rad), the Genotyping Master Mix (Applied Biosystems) and the QuantiTect Multiplex Mix (Qiagen) were tested on 50 ng of bisulfite treated SiHa DNA, which is positive for CADM1, MAL and hsa-miR-124-2 methylation. The reactions were performed in triplicate using multiplex qMSP conditions as outlined in the Materials and Methods section. The fluorescence data with the different TaqMan buffer systems were collected to determine the $\mathrm{Cq}$ at a threshold of 0.01 and the highest maximum fluorescent signal $(\Delta \mathrm{Rn}$ at $\mathrm{Cq}=40)$. The most optimal TaqMan buffer system for multiplex qMSP should have a low Cq value combined with a high $\Delta \mathrm{Rn}$. The Genotyping Master Mix gave the highest $\mathrm{Cq}$ values combined with the highest $\Delta \mathrm{Rn}$ values, indicating that this master mix is not ideal for multiplex qMSP (Table 1). Reactions that used iQ Multiplex Powermix revealed the highest maximum $\Delta \mathrm{Rn}$. However, as the minimum $\Delta \mathrm{Rn}(\mathrm{Cq}=0)$ was relatively high, the threshold needed to be adjusted to 0.1. This adjustment resulted in the lowest $\mathrm{Cq}$ values, which could not be 


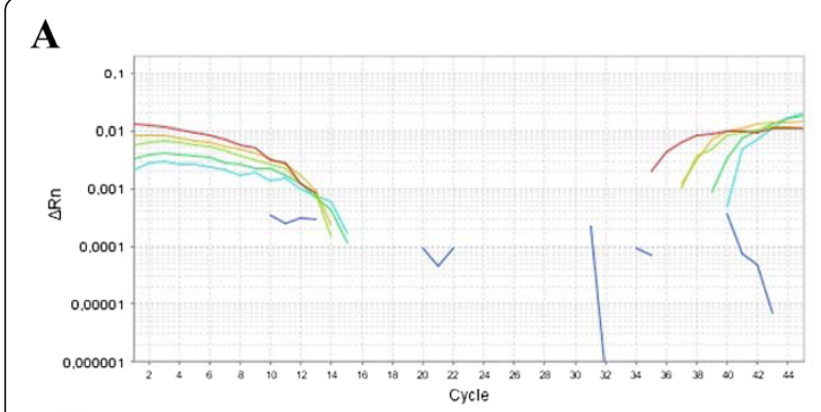

C

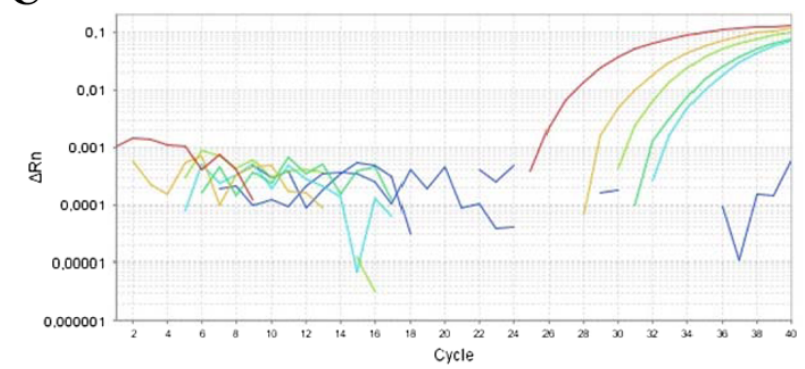

$\mathbf{E}$

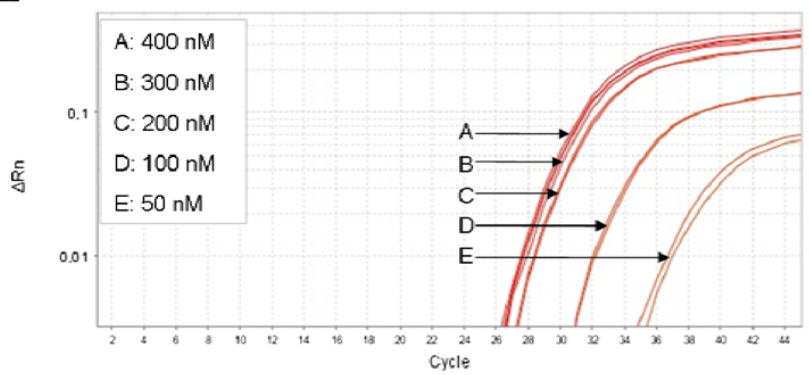

B

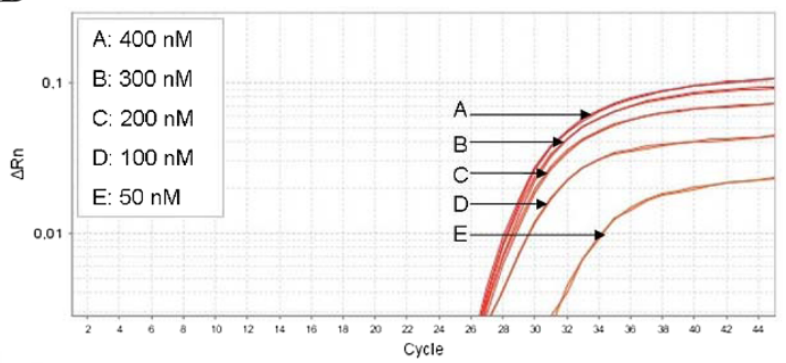

D

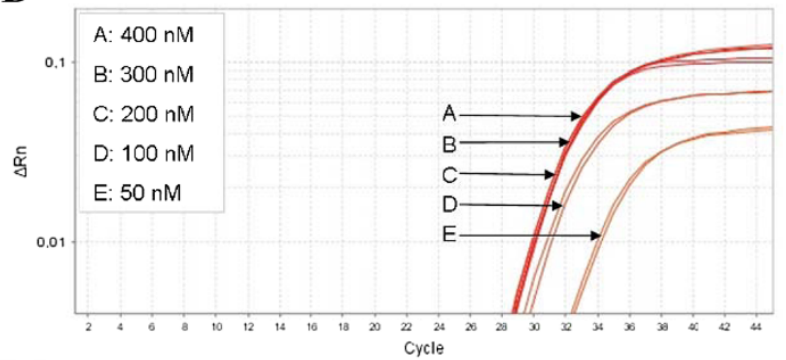

F

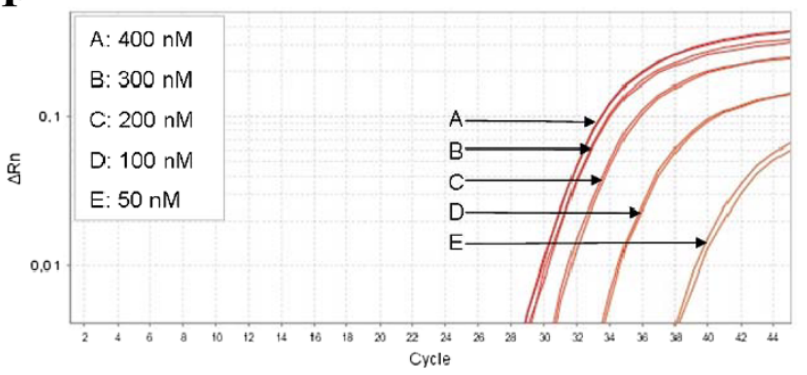

Figure 3 Primer-limiting assays for ACTB, CADM1, MAL and hsa-miR-124-2. (A) Amplification curve of MAL in a multiplex qMSP with ACTB. When ACTB-primers are used at a concentration of $400 \mathrm{nM}$, there is little to no amplification of MAL, which could be due to dNTP depletion by ACTB. (B) The minimum primer concentration of ACTB was $200 \mathrm{nM}$. (C) When the ACTB-primer concentration was lowered to $200 \mathrm{nM}$ MAL amplification was not hampered. The minimum primer concentration was $200 \mathrm{nM}$ for CADM1 (D), and $400 \mathrm{nM}$ for MAL (E) and miR-124-2 (F).

compared to the Cq values obtained with the other reaction mixtures due to differences in thresholds. With the iQ Multiplex Powermix the amplification curves for all targets had relatively small exponential phases, resulting in a small range for determining the most optimal threshold. The $\mathrm{Cq}$ and $\Delta \mathrm{Rn}$ values obtained with EpiTect Methylight and QuantiTect Multiplex buffer systems were comparable. Due to the convenience of the presence of the passive reference ROX in the QuantiTect Multiplex buffer, which was not in the EpiTect Methylight mix for multiplexing on a ABI7500, the QuantiTect Multiplex mix was used in subsequent optimization experiments.

\section{Analytical validation of the multiplex qMSP}

Using a serial dilution series of methylated DNA in unmethylated DNA, the performance of the designed multiplex qMSP was compared to the singleplex qMSP (Figure 4). The correlation $\left(\mathrm{R}^{2}\right)$ for all the singleplex and multiplex qMSPs were higher than 0.99, indicating high linearity (Figure 4A-C). Whereas the Cq values, when determined at a threshold of 0.01 , differed between singleplex and multiplex qMSP, same Cq values were obtained when adjusting the thresholds, resulting in overlapping standard curves. In addition, high efficiencies, ranging from $87 \%$ to $94 \%$ for singleplex qMSP and $92 \%$ to $109 \%$ for multiplex qMSP, were found. This indicates that there is no qMSP inhibition upon multiplexing ACTB, CADM1, MAL and hsa-miR-124-2. The high reproducibility of the multiplex qMSP is demonstrated in Additional file 1, showing the results of 10 independent multiplex qMSP runs on a serial dilution of 50 to $0.05 \mathrm{ng}$ of methylated DNA in a background of unmethylated DNA. 
Table 1 Multiplex qMSP results using different TaqMan buffer systems ${ }^{*}$

\begin{tabular}{llccrr}
\hline Primers & Parameter & $\begin{array}{c}\text { EpiTect MethyLight } \\
\text { Mix (Qiagen) }\end{array}$ & $\begin{array}{c}\text { iQ Multiplex Powermix } \\
\text { (Bio-Rad) }\end{array}$ & $\begin{array}{c}\text { Genotyping Master } \\
\text { Mix (ABI) }\end{array}$ & $\begin{array}{c}\text { QuantiTect Multiplex } \\
\text { Mix (Qiagen) }\end{array}$ \\
\hline ACTB & $\mathbf{C q}$ & $27.19 \pm 0.093$ & $26.712 \pm 0.072$ & $28.448 \pm 0.933$ & $27.972 \pm 0.032$ \\
\hline CADM1 & $\mathbf{A R n}$ & $0.244 \pm 0.004$ & $2.655 \pm 0.003$ & $0.791 \pm 0.090$ & $0.170 \pm 0.003$ \\
\hline MAL & $\mathbf{C R n}$ & $28.216 \pm 0.130$ & $27.485 \pm 0.038$ & $28.463 \pm 0.341$ & $28.888 \pm 0.103$ \\
\hline & $\mathbf{C q}$ & $0.267 \pm 0.006$ & $2.722 \pm 0.038$ & $1.160 \pm 0.056$ & $0.182 \pm 0.004$ \\
\hline Hsa-miR-124-2 & $\mathbf{A R n}$ & $26.432 \pm 0.170$ & $25.593 \pm 0.030$ & $29.499 \pm 0.837$ & $26.759 \pm 0.053$ \\
\hline & $\mathbf{C q}$ & $0.371 \pm 0.022$ & $2.662 \pm 0.026$ & $1.003 \pm 0.203$ & $0.282 \pm 0.023$ \\
\hline
\end{tabular}

${ }^{*}$ Triplicate analyses of $50 \mathrm{ng}$ of bisulfite treated SiHa DNA. Mean values are indicated \pm standard deviations.

*** Threshold 0.1 .
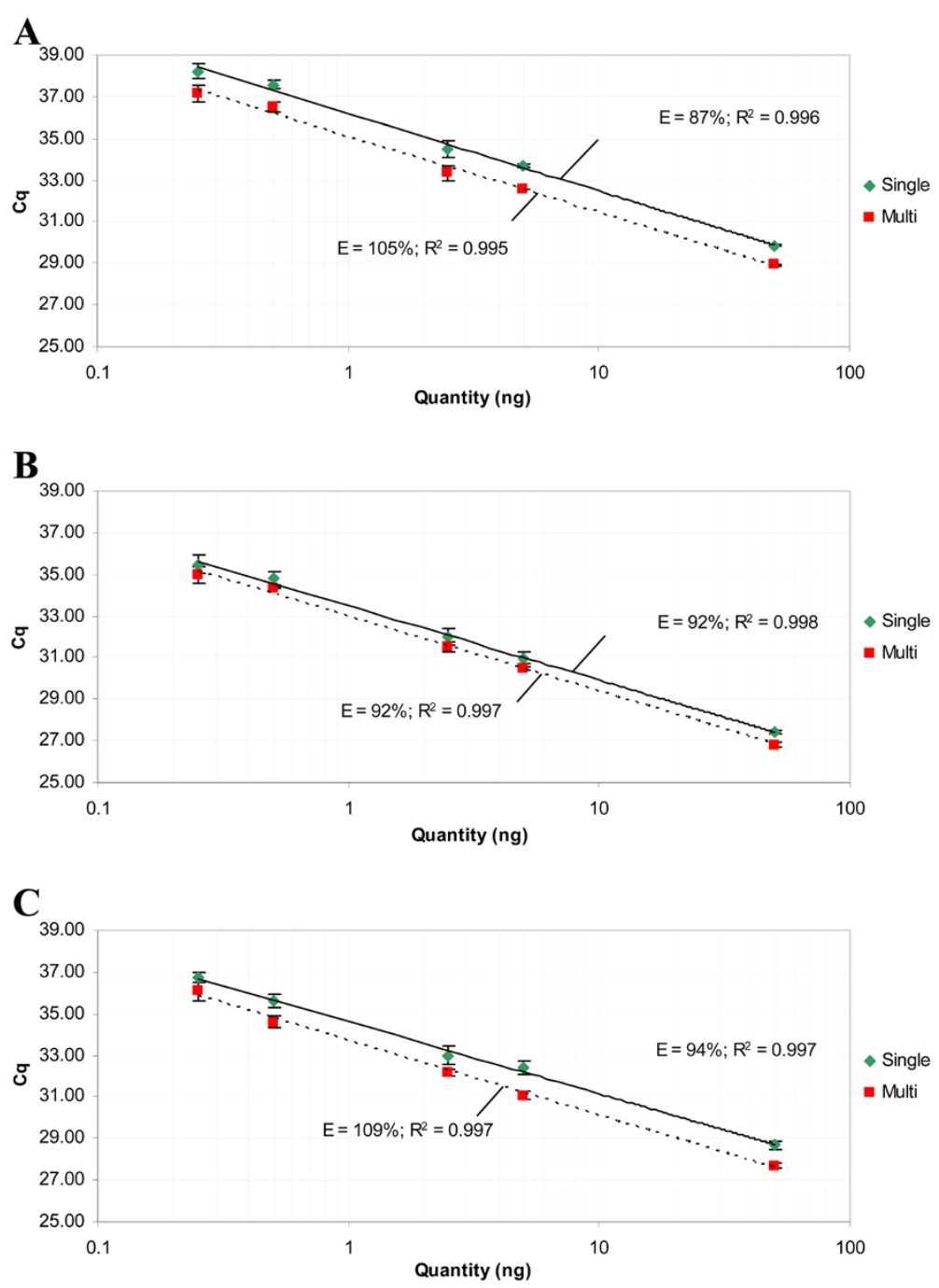

Figure 4 High linearity between singleplex and multiplex analysis on serial dilutions of methylated DNA (SiHa) in unmethylated DNA (EK). The multiplex reactions showed comparable efficiencies as the singleplex reactions for CADM1 (A), MAL (B) and hsa-miR-124-2 (C). Same thresholds were used in singleplex and multiplex GMSP, resulting in different Cq values for all targets. When adjusting the thresholds, the same Cq values can be obtained, resulting in overlap of the standard curves. 


\section{Evaluation of multiplex qMSP on cervical scrapings}

Eventually, the multiplex qMSP was tested on 45 hrHPV-positive cervical scrapings. The normalized ratios of singleplex qMSPs of the cervical scrapings correlated strongly to those of multiplex qMSP for all three markers (Figure 5A-C). Correlation coefficients were as follows: $R^{2}=0.985, R^{2}=0.986$ and $R^{2}=0.944$ for CADM1, MAL and hsa-miR-124-2, respectively. Of note, the same Cq ratios between singleplex and multiplex qMSP could be obtained when adjusting the threshold settings for all three markers and ACTB. These results indicate that the developed multiplex qMSP assay shows an equal performance in detection methylation in these samples as the singleplex qMSPs.

\section{Discussion}

Here, we describe the development of a multiplex qMSP analysis for the methylation markers CADM1, MAL and hsa-miR-124-2 and the reference gene ACTB. To obtain a multiplex qMSP, primers were adjusted to acquire identical annealing temperatures to enable similar amplification efficiencies for all targets. Multiplex TaqMan buffer systems were compared and primer concentrations were limited to allow efficient amplification of all targets. Analytical validation using a dilution series of methylated DNA spiked with unmethylated DNA showed an equal performance of the multiplex qMSP compared to the individual singleplex qMSPs. Moreover, the multiplex qMSP was found to be very robust,
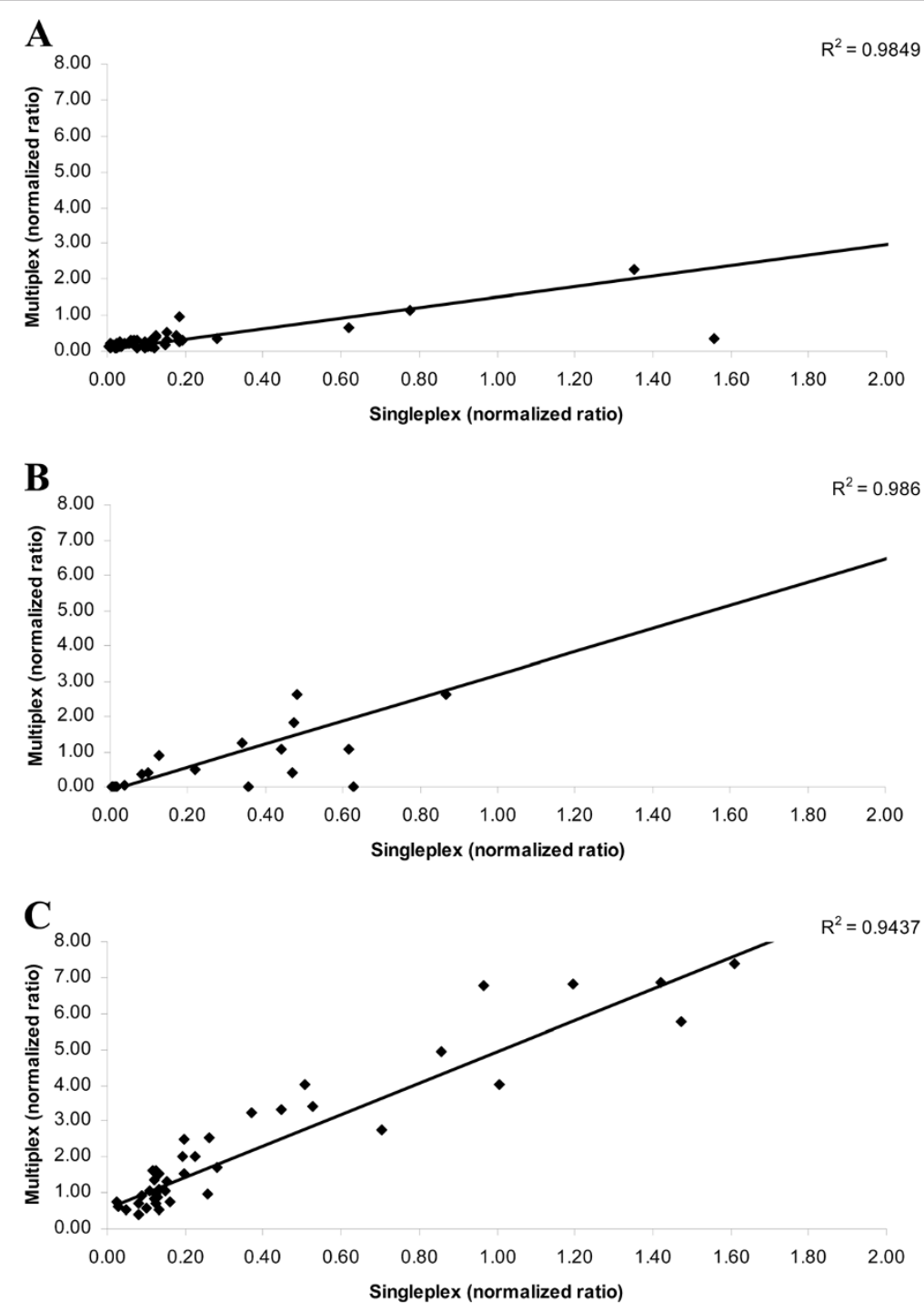

Figure 5 Correlation between the $\Delta$ Cq values obtained with singleplex and multiplex qMSP. The $R^{2}$ values for the three markers were 0.985, 0.986 and 0.944 for CADM1 (A), MAL (B) and hsa-miR-124-2 (C), respectively. The $\Delta$ Cq values between singleplex and multiplex qMSP differ, due to differences in set thresholds. 
showing high reproducibility across 10 independent experiments. Further evaluation on cervical scrapings revealed a high correlation between the obtained normalized ratios of the singleplex qMSPs and the multiplex qMSP. Based on our experience obtained by optimizing a multiplex qMSP, a guideline is designed (Figure 1), describing the consecutive experimental steps for multiplex qMSP set up.

Major advantages of multiplexing are less hands-on time and less amounts of DNA required to determine the methylation status of multiple methylation markers as compared to running multiple singleplex analyses. Moreover, freeze-thawing of bisulfite modified DNA, which is inherent to repetitive singleplex analysis may degrade the single-stranded DNA, resulting in increased Cq values [24]. Another advantage is the improved data quality, because the methylation marker is normalized to the reference gene present in the same reaction, thereby reducing the potential negative impact of for example pipetting errors when the reference gene is tested in a separate reaction. These features of multiplex qMSP are extremely beneficial for molecular diagnostics.

Both the EpiTect Methylight and QuantiTect Multiplex Mix buffer systems could be used for multiplex qMSP. Other TaqMan buffer systems, such as the Genotyping Master Mix and the iQ Multiplex Powermix are less favorable for multiplex analysis, due to high $\mathrm{Cq}$ values/low $\Delta \mathrm{Rn}$ or low linear phase amplifications. With this optimized multiplex qMSP, the normalized ratios obtained from cervical scrapings correlated strongly with those of the individual singleplex assays.

The development of a multiplex qMSP has been described before in a study on colorectal cancer [25]. In this study the dyes, FAM, Hex CY5 and Texas Red were used, the latter of which prohibits the use of ROX as a passive reference to normalize for non-PCR-related fluctuations in fluorescence signal. Moreover, it is unknown whether the relatively high concentration of ACTB primers used, affected amplification of the other targets, as no primer limiting assays were described. Others have proposed the combination of a circularizing oligonucleotide probe, the so-called target-selection-padlock probes, with microarray technology as a high-throughput approach for DNA methylation detection [26]. However, with this technique hundreds of genes are analyzed, while only several methylation markers are needed for diagnostic use. Another promising multiplex technique is the recently described quantitative allele-specific realtime target and signal amplification (QuARTS), which showed to be highly sensitive [27]. Future studies will show its potential value in a diagnostic setting.

The analytical performance of the multiplex qMSP could potentially be further improved by the incorporation of Locked Nucleic Acids (LNAs) in primers and/or hydrolysis probes [28], as has been described for singleplex MGMT
[29] and CADM1 [30] qMSPs. In analogy to its use for improved DNA mutation analysis (as was reviewed by [31]), peptide nucleic acid (PNA) hybridization probes, in which the sugar-phosphate backbone of DNA is replaced by a pseudopeptide and very stable heteroduplexes can be formed. This would prevent amplification of unmethylated DNA, thereby enhancing the analytical performance of qMSP. The impact of such modification on the clinical performance of methylation analysis warrants further evaluation.

The multiplex qMSP described here was performed on an ABI7500 Fast Real-Time PCR System, which supports multiplexing of five targets, when ROX is not present in the buffer system. In principle, even more methylation markers can be incorporated into the multiplex qMSP, when other devices will be used, such as the $\mathrm{ViiA}^{\mathrm{TM}}$ 7 Real-Time PCR System (Applied Biosystems) or the LightCycler 480 (Roche), which support multiplexing of six targets. We were however unable to develop a multiplex qMSP on the ABI7900HT Fast Real-Time PCR System, which may be related to the differences in detection systems.

The CADM1, MAL, hsa-miR-124-2 multiplex methylation assay described here may serve as a triage test for hrHPV-positive women in population-based screening. We recently demonstrated that combined CADM1 and MAL promoter methylation analysis on physician-taken cervical scrapings of hrHPV-positive women was at least equally discriminatory for high-grade CIN as cytology or cytology combined with HPV16/18 genotyping [14]. Futhermore, these methylation markers are applicable to self-collected cervico-vaginal lavage specimens for colposcopy triage of hrHPV-positive women (Hesselink et. al, unpublished observations) and are currently tested prospectively [32].

\section{Conclusion}

In summary, multiplex qMSP is a high-throughput, quantitative assay to analyze multiple methylation markers in a single reaction. It showed to be equally specific, sensitive and reproducible as its singleplex versions. Due to the material saving capacity, the multiplex qMSP may allow analysis of samples with limited methylated DNA content, such as bodily fluids, like urine, blood or sputum. Multiplex qMSP can be applied to cervical scrapes and selfcollected specimens and used as a triage tool for detection of high-grade cervical lesions in hrHPV-positive women.

\section{Additional file}

Additional file 1: Reproducibility of multiplex qMSP. Serial dilutions of methylated DNA ( $\mathrm{SiHa}$ ) spiked with unmethylated DNA (EK) in order to obtain a serial dilution of $50 \mathrm{ng}$ to $0.25 \mathrm{ng}$ methylated DNA in a total of 50 ng of DNA, showed high reproducibility when testing the multiplex qMSP in 10-fold. 


\section{Competing interests}

Dr. R.D.M. Steenbergen, Dr. D.A.M. Heideman, Prof. dr. P.J.F. Snijders and Prof. dr. C.J.L.M. Meijer have relationships with Self-screen BV, The Netherlands.

\section{Authors' contributions}

SS developed and analytically validated the multiplex GMSP. LDS and ATH evaluated the multiplex qMSP on cervical scrapings. RDMS and PJFS designed the study and participated in data analysis and interpretation. SS drafted the original manuscript. RDMS, DAMH, PJFS and CJLMM critically revised the manuscript. All authors have read and approved of the final manuscript.

\section{Acknowledgements}

We thank Dr. W.F. van der Meide and H.M.E. de Bruin for excellent advice and technical assistance. This work was supported by the Dutch Cancer Society (VU-2007-3771; VU 2009-4522).

Received: 12 June 2012 Accepted: 8 November 2012 Published: 23 November 2012

\section{References}

1. Walboomers JM, Jacobs MV, Manos MM, Bosch FX, Kummer JA, Shah KV, Snijders PJ, Peto J, Meijer CJ, Munoz N: Human papillomavirus is a necessary cause of invasive cervical cancer worldwide. J Pathol 1999, 189(1):12-19.

2. Zielinski GD, Rozendaal L, Voorhorst FJ, Berkhof J, Snijders PJ, Risse EJ, Runsink AP, de Schipper FA, Meijer CJ: HPV testing can reduce the number of follow-up visits in women treated for cervical intraepithelial neoplasia grade 3. Gynecol Oncol 2003, 91(1):67-73.

3. Naucler P, Ryd W, Tornberg S, Strand A, Wadell G, Elfgren K, Radberg T, Strander B, Johansson B, Forslund O, et al: Human papillomavirus and Papanicolaou tests to screen for cervical cancer. N Engl J Med 2007, 357(16):1589-1597.

4. Rijkaart DC, Berkhof J, Rozendaal L, van Kemenade FJ, Bulkmans NW, Heideman DA, Kenter GG, Cuzick J, Snijders PJ, Meijer CJ: Human papillomavirus testing for the detection of high-grade cervical intraepithelial neoplasia and cancer: final results of the POBASCAM randomised controlled trial. Lancet Oncol 2012, 13(1):78-88.

5. Ronco G, Giorgi-Rossi P, Carozzi F, Confortini M, Dalla Palma P, Del Mistro A, Gillio-Tos A, Minucci D, Naldoni C, Rizzolo R, et al: Results at recruitment from a randomized controlled trial comparing human papillomavirus testing alone with conventional cytology as the primary cervical cancer screening test. J Natl Cancer Inst 2008, 100(7):492-501.

6. Eijsink JJ, Yang N, Lendvai A, Klip HG, Volders HH, Buikema HJ, van Hemel BM, Voll M, Coelingh Bennink HJ, Schuuring E, et al: Detection of cervical neoplasia by DNA methylation analysis in cervico-vaginal lavages, a feasibility study. Gynecol Oncol 2011, 120(2):280-283.

7. Kim JH, Choi YD, Lee JS, Lee JH, Nam JH, Choi C: Assessment of DNA methylation for the detection of cervical neoplasia in liquid-based cytology specimens. Gynecol Oncol 2010, 116(1):99-104.

8. Overmeer RM, Henken FE, Bierkens M, Wilting SM, Timmerman I, Meijer CJ, Snijders PJ, Steenbergen RD: Repression of MAL tumour suppressor activity by promoter methylation during cervical carcinogenesis. J Pathol 2009, 219(3):327-336.

9. Overmeer RM, Louwers JA, Meijer CJ, van Kemenade FJ, Hesselink AT, Daalmeijer NF, Wilting SM, Heideman DA, Verheijen RH, Zaal A, et al: Combined CADM1 and MAL promoter methylation analysis to detect (pre-)malignant cervical lesions in high-risk HPV-positive women. Int J Cancer 2010, 129(9):2218-2225.

10. Overmeer RM, Henken FE, Snijders PJ, Claassen-Kramer D, Berkhof J, Helmerhorst TJ, Heideman DA, Wilting SM, Murakami Y, Ito A, et al: Association between dense CADM1 promoter methylation and reduced protein expression in high-grade CIN and cervical SCC. J Pathol 2008, 215(4):388-397.

11. Wilting SM, van Boerdonk RA, Henken FE, Meijer CJ, Diosdado B, Meijer GA, le Sage C, Agami R, Snijders PJ, Steenbergen RD: Methylation-mediated silencing and tumour suppressive function of hsa-miR-124 in cervical cancer. Mol Cancer 2010, 9:167.

12. Wentzensen $N$, Sherman ME, Schiffman M, Wang SS: Utility of methylation markers in cervical cancer early detection: appraisal of the state-of-the-science. Gynecol Oncol 2009, 112(2):293-299.
13. Kahn SL, Ronnett BM, Gravitt PE, Gustafson KS: Quantitative methylation-specific PCR for the detection of aberrant DNA methylation in liquid-based Pap tests. Cancer 2008, 114(1):57-64.

14. Hesselink AT, Heideman DA, Steenbergen RD, Coupe VM, Overmeer RM, Rijkaart D, Berkhof J, Meijer CJ, Snijders PJ: Combined promoter methylation analysis of CADM1 and MAL: an objective triage tool for high-risk human papillomavirus DNA-positive women. Clin Cancer Res 2011, 17(8):2459-2465.

15. Eijsink JJ, Lendvai A, Deregowski V, Klip HG, Verpooten G, Dehaspe L, de Bock GH, Hollema H, van Criekinge W, Schuuring E, et al: A four-gene methylation marker panel as triage test in high-risk human papillomavirus positive patients. Int J Cancer 2012, 130(8):1861-1869.

16. Feng Q, Balasubramanian A, Hawes SE, Toure P, Sow PS, Dem A, Dembele B, Critchlow CW, Xi L, Lu H, et al: Detection of hypermethylated genes in women with and without cervical neoplasia. J Natl Cancer Inst 2005, 97(4):273-282.

17. Steenbergen RD, Kramer D, Braakhuis BJ, Stern PL, Verheijen RH, Meijer CJ, Snijders PJ: TSLC1 gene silencing in cervical cancer cell lines and cervical neoplasia. J Natl Cancer Inst 2004, 96(4):294-305.

18. Bulkmans NW, Berkhof J, Rozendaal L, van Kemenade FJ, Boeke AJ, Bulk S, Voorhorst FJ, Verheijen RH, van Groningen K, Boon ME, et al: Human papillomavirus DNA testing for the detection of cervical intraepithelial neoplasia grade 3 and cancer: 5-year follow-up of a randomised controlled implementation trial. Lancet 2007, 370(9601):1764-1772.

19. Snijders PJ, van den Brule AJ, Jacobs MV, Pol RP, Meijer CJ: HPV DNA detection and typing in cervical scrapes. Methods Mol Med 2005, 119:101-114.

20. Schmittgen TD, Livak KJ: Analyzing real-time PCR data by the comparative C(T) method. Nat Protoc 2008, 3(6):1101-1108.

21. Pfaffl MW: A new mathematical model for relative quantification in real-time RT-PCR. Nucleic Acids Res 2001, 29(9):e45.

22. Henegariu O, Heerema NA, Dlouhy SR, Vance GH, Vogt PH: Multiplex PCR: critical parameters and step-by-step protocol. Biotechniques 1997, 23(3):504-511.

23. Barekati Z, Radpour R, Kohler C, Zhong XY: Specificity of methylation assays in cancer research: a guideline for designing primers and probes. Obstet Gynecol Int 2010, Epub 2010 Jul 27.

24. Dallol A, Al-Ali W, Al-Shaibani A, Al-Mulla F: Analysis of DNA methylation in FFPE tissues using the MethyLight technology. Methods Mol Biol 2011, 724:191-204.

25. He Q, Chen HY, Bai EQ, Luo YX, Fu RJ, He YS, Jiang J, Wang HQ: Development of a multiplex MethyLight assay for the detection of multigene methylation in human colorectal cancer. Cancer Genet Cytogenet 2010, 202(1):1-10.

26. Shi X, Tang C, Zhou D, Zhao H, Lu Z: Multiplex detection of CpG methylation using microarray combining with target-selection-padlock probe. Clin Chim Acta 2010, 411(17-18):1187-1194.

27. Zou H, Allawi H, Cao X, Domanico M, Harrington J, Taylor W, Yab T, Ahlquist DA, Lidgard G: Quantification of Methylated Markers with a Multiplex Methylation-Specific Technology. Clin Chem 2011, 58(2):375-383.

28. Vester B, Wengel J: LNA (locked nucleic acid): high-affinity targeting of complementary RNA and DNA. Biochemistry 2004, 43(42):13233-13241.

29. Morandi L, Franceschi E, de Biase D, Marucci G, Tosoni A, Ermani M, Pession A Tallini G, Brandes A: Promoter methylation analysis of O6-methylguanineDNA methyltransferase in glioblastoma: detection by locked nucleic acid based quantitative PCR using an imprinted gene (SNURF) as a reference. BMC Cancer 2010, 10:48.

30. Gustafson KS: Locked nucleic acids can enhance the analytical performance of quantitative methylation-specific polymerase chain reaction. J Mol Diagn 2008, 10(1):33-42.

31. Pellestor F, Paulasova P, Hamamah S: Peptide nucleic acids (PNAs) as diagnostic devices for genetic and cytogenetic analysis. Curr Pharm Des 2008, 14(24):2439-2444.

32. The Health Council of the Netherlands. http://www.gr.nl/en.

\section{doi:10.1186/1471-2407-12-551}

Cite this article as: Snellenberg et al:: Development of a multiplex methylation-specific PCR as candidate triage test for women with an HPV-positive cervical scrape. BMC Cancer 2012 12:551. 